\title{
DIGITAL CONSUMER INSIGHT UNTUK MEMBANGUN PROMOSI BAGI UKM DI LINGKUNGAN TANGERANG KOTA
}

\author{
Nindyta Aisyah Dwityas ${ }^{*}$, Sri Hesti \\ Program Studi IImu Komunikasi, Fakultas Ilmu Komunikasi, Universitas Mercu Buana, Indonesia \\ E-mail: nindyta.aisyah@mercubuana.ac.id*, sri.hesti@mercubuana.ac.id \\ Received: August 22, 2020 / Revised: December 10, 2020 / Accepted: April 26, 2021 \\ DOI: https://doi.org/10.36782/ijsr.v3i1.45
}

\begin{abstract}
ABSTRAK
Kegiatan edukasi mengenai digital consumer insight untuk membangun promosi UKM di lingkungan Tangerang Kota dilaksanakan dengan tujuan untuk membantu para pelaku bisnis skala mikro dan kecil di lingkungan Tangerang Kota dalam upaya mengembangkan bisnis yang mereka jalankan. Kegiatan ini diikuti oleh 22 (dua puluh dua) peserta dan telah dilaksanakan di Kelurahan Cibodas pada Maret 2020. Metode yang digunakan adalah dengan 1) penyuluhan dan pengenalan mengenai pengembangan bisnis secara online khususnya tentang perilaku konsumen di era digital, 2) edukasi mengenai aktivitas dan tahapan yang dilalui oleh konsumen dalam mengambil keputusan pembelian di berbagai platform online, 3) penyampaian tutorial penyusunan strategi targeting untuk menyasar konsumen di platform online, 4) tutorial pemanfaatan hasil analisa informasi aktivitas konsumen untuk mengembangkan strategi komunikasi pemasaran di platform online, 5) diskusi interaktif, dan 6) evaluasi kegiatan. Secara khusus pengembangan bisnis difokuskan pada aktivitas promosi di platform online dengan memanfaatkan informasi mengenai perilaku konsumen di era digital. Adapun informasi tersebut merupakan hasil penelitian yang pernah dilakukan sebelumnya mengenai "consumer journey di media sosial". Hasil kegiatan pengabdian masyarakat ini adalah terbangunnya pemahaman peserta terkait perilaku konsumen di media sosial, peningkatan pemahaman dan kemampuan peserta dalam memanfaatkan berbagai fitur dan fasilitas media sosial untuk kepentingan bisnis, dan peningkatan kemampuan peserta dalam membuat konten bisnis di media sosial. Sebagai kesimpulan diketahui bahwa kegiatan pengabdian masyarakat yang diarahkan pada peningkatan pemahaman dan kemampuan teknis pelaku UMKM perlu terus dilakukan dan dikembangkan untuk mendukung pemberdayaan sektor industri mikro, kecil, dan menengah di Indonesia.
\end{abstract}

Kata kunci: Consumer Insight, Media Promosi Online, Perilaku Konsumen.

\section{ABSTRACT}

Educational activities about digital consumer insight to build SME promotions in the Tangerang City environment are carried out to help micro and small-scale businesses in the Tangerang City environment to develop the businesses they run. This activity was attended by 22 participants and was held in Cibodas Village in March 2020. The method used is 1) counseling and introduction to online business development, especially regarding consumer behavior in the digital era, 2) education about the activities and stages that consumers go through in making purchase decisions on various online platforms, 3) tutorials for consumers targeting on online 
platforms, 4) tutorials on utilizing the results of analysis of consumer information to develop marketing communication strategies in online platforms, 5) interactive discussions, and 6) evaluation. In particular, business development is focused on promotional activities on online platforms by utilizing information about consumer behavior in the digital era. This information is the result of previous research on the "consumer journey on social media". The result of this community service activity is the development of participant understanding regarding consumer behavior on social media, increased understanding and ability of participants in utilizing various features and facilities of social media for business purposes, and increasing participants' ability to create business content on social media. In conclusion, it is known that community service activities aimed at increasing the understanding and technical capabilities of MSME actors need to be carried out and developed to support the empowerment of the micro, small, and medium industrial sector in Indonesia.

Keywords: Consumer Behavior, Consumer Insight, Online Promotion Media.

\section{PENDAHULUAN}

Sejak awal perkembangannya teknologi internet telah merubah aktivitas sosial dan ekonomi manusia. Internet merevolusi sebagian besar kehidupan manusia yang terlihat dari aktivitas berkomunikasi, bekerja dan berbisnis (Gane \& Beer, 2008). Kemunculan berbagai macam platform komunikasi dan interaksi beserta fitur yang sangat beragam memfasilitasi aktivitas bisnis manusia (Briandana et al., 2020). Tidak saja pada kegiatan jual-beli, teknologi ini bahkan menawarkan sumber data yang tak terhingga yang sangat bermanfaat bagi penyusunan strategi pemasaran utamanya untuk kepentingan promosi (Dwityas, Mulyana, et al., 2020).

Teknologi komunikasi dan informasi tidak hanya berperan besar bagi praktik-praktik penyampaian pesan yang dilakukan oleh perusahaan/organisasi, dengan berkembangnya komunitas-komunitas berbasis konsumen di berbagai platform ICT memungkinkan perusahaan dan organisasi untuk mengumpulkan, mengelola dan memanfaatkan data-data konsumen untuk membangun strategi pemasaran yang dapat diarahkan secara lebih personal (Mulyana et al., 2020).

Komunitas konsumen dalam jaringan tersebar dalam berbagai platform utamanya media sosial (Kim et al., 2004). Media sosial menjadi salah satu platform terbesar yang memfasilitasi konsumen dalam menyebarluaskan berbagai informasi tentang perusahaan atau produk (Harrigan et al., 2017). Informasi yang terbangun dari konten-konten yang diunggah oleh pengguna dikenal dengan istilah user created/generated content (UCC/UGC). UCC/UGC didefinisikan sebagai informasi yang muncul baik dalam bentuk teks, visual hingga audio-visual yang secara khusus diciptakan, dikumpulkan, dan disebarkan oleh para konsumen itu sendiri (Dwityas, 2016).

Di media sosial salah satu konten terkait produk (product-related content) yang paling 
banyak diunggah oleh pengguna media sosial adalah produk kuliner. Hollebeek et al., (2014), menemukan bahwa foto makanan menempati posisi tiga teratas yang paling banyak di unggah di Instagram setelah swafoto dan foto bersama kerabat. Popularitas produk kuliner dalam media sosial khususnya Instagram terus meningkat seiring dengan maraknya kemunculan akun-akun food blogger, hingga komunitas-komunitas yang mengkhususkan diri dalam membahas konten mengenai pengalaman makan dan produkproduk yang terkait (Wang et al., 2012).

Dalam komunitas media sosial tersebut dapat terjadi ribuan interaksi. Interaksi tersebut dapat muncul dalam bentuk komentar atau respon menyukai. Dalam komunitas virtual ini, pecinta kuliner juga bergabung menjadi anggota untuk berinteraksi, berkolaborasi dan berbagi informasi dengan anggota komunitas lainnya (Sidali et al., 2015).

Melalui hasil penelitian Consumer Journey dalam Media Sosial, Dwityas, N., dkk., (2020) mengungkapkan bahwa aktivitas konsumen produk kuliner dalam media sosial menunjukkan sebuah proses kompleks terkait pengambilan keputusan pembelian yang secara lengkap yang dimulai dari tahap aware, appeal, ask, act, hingga advocate (Dwityas, Briandana, et al., 2020). Proses ini dapat terlihat dari aktivitas penyebaran informasi, penyampaian respon ketertarikan melalui komentar dan tombol suka, keterlibatan pengguna dalam diskusi mengenai produk kuliner, hingga pemberian testimoni dan rekomendasi dari sesama anggota komunitas (Dwityas, Briandana, et al., 2020).

Hal ini menjadi masukan penting bagi pelaku bisnis kuliner khususnya untuk membangun strategi pemasaran yang disesuaikan dengan perilaku konsumen di era digital. Tidak hanya untuk pelaku bisnis berskala besar. Pelaku bisnis dalam skala UKM juga dapat memanfaatkan informasi ini untuk menjalankan dan mengembangkan bisnis mereka untuk tujuantujuan yang lebih besar. Hal ini juga didorong dengan pesatnya ketersediaan fasilitas-fasilitas teknologi komunikasi dan informasi yang disediakan berbagai pengembang aplikasi khususnya sebagai perantara antara pelaku bisnis UMKM dengan konsumennya.

Terkait dengan latar belakang tersebut, kegiatan Pengabdian pada Masyarakat ini dilakukan. Dengan harapan tanggung jawab Tri Dharma Perguruan Tinggi dapat memberikan manfaat konkrit bagi pengembangan masyarakat khususnya dalam pemberdayaan bisnis UMKM di Indonesia.

Dari analisis situasi diketahui besarnya peluang yang dapat tercipta bagi para pelaku bisnis dengan upaya-upaya peningkatan penguasaan teknologi komunikasi dan informasi khususnya terkait pemahaman mengenai perilaku konsumen di era digital. Perusahaanperusahaan berskala besar atau multi nasional tentunya akan lebih mudah menguasai bidang ini dengan kecukupan sumber daya yang mereka miliki. Yang menjadi permasalahan adalah apa 
yang dihadapi oleh para pelaku bisnis Usaha Mikro Kecil Menengah (UMKM) dengan keterbatasan sumber daya baik riil maupun materiil yang mereka miliki. Hal ini lah yang melatarbelakangi ketertarikan untuk mengadakan pelatihan terkait topik ini kepada UMKM di daerah Tangerang Kota.

Usaha berskala UMKM memang menjadi andalan penduduk Kota Tangerang. Dominasi jumlah usaha dengan skala UMK, menunjukkan UMK merupakan sumber pendapatan utama masyarakat di Kota Tangerang dengan jumlah pelaku usaha yang terus meningkat dari tahun ke tahun. Kabid UKM pada Dinas Koperasi dan UKM, Katrina Iswandari mengatakan, berdasarkan data UMKM pada 2016 berjumlah 10.553. Kemudian bertambah di 2017 menjadi 10.675, di tahun berikutnya meningkat kembali menjadi 11.746 dan terakhir 2019 sampai bulan April mencapai 12.508 pelaku

UMKM

(umkm.tangerangkota.go.id, 2020).

Tingginya jumlah UMKM di daerah Tangerang Kota belum diimbangi dengan pemanfaatkan teknologi internet secara memadai. Untuk itu agar dapat menjalankan promosi bisnis UMKM secara maksimal, perlu dukungan dari berbagai pihak, salah satunya melalui pelatihan-pelatihan semacam ini. Pemasaran serta promosi barang dan jasa masih banyak dilakukan secara konvensional, menjadi salah satu kendala kurang berkembangnya bisnis yang mereka lakukan. Jika dibiarkan, keadaan tersebut dapat berpengaruh secara negatif pada keberlangsungan bisnis mereka, terlebih persaingan yang terjadi pada masa ini dan yang akan datang akan memberikan tantangan dan ancaman signifikan bagi keberhasilan bisnisbisnis masyarakat skala kecil menengah. Di satu sisi peluang untuk memasarkan produk-produk home industry akan semakin terbuka lebar, hal ini lah yang juga perlu dicermati agar UMKM di Indonesia mampu bersaing dan berkembang.

Adapun tujuannya adalah memberikan pemahaman dan keterampilan pelaku bisnis UMKM di lingkungan Tangerang Kota terkait perilaku konsumen (consumer insight) khususnya pengambilan keputusan pembelian mereka di era digital yang selanjutnya bisa dimanfaatkan untuk membangun strategi promosi.

\section{METODOLOGI}

Kegiatan pengabdian pada masyarakat dengan judul "Digital Consumer Insight untuk Membangun Promosi bagi UKM di Lingkungan Tangerang Kota" telah dilaksanakan di Kelurahan Cibodas pada tanggal 5 Maret 2020.

Kegiatan ini dihadiri oleh 22 (dua puluh dua) peserta yang hadir, masing-masing peserta merupakan masyarakat yang memiliki/mengelola bisnis berskala kecilmenegah. Adapun kategori bisnis yang digeluti oleh para peserta cukup beragam, namun didominasi oleh penggiat bisnis kuliner. Selama proses pelatihan, peserta secara tertib mengikuti keseluruhan rangkaian kegiatan dan sebagian 
besar aktif dalam aktivitas diskusi dan tanyajawab.

Metode pelaksanaan kegiatan pelatihan Digital Consumer Insight untuk membangun promosi bagi UKM ini dilakukan dengan beberapa rangkaian atau tahapan kegiatan, yaitu:

1. Ceramah dan penjelasan terperinci mengenai pengembangan bisnis secara online khususnya tentang perilaku konsumen di era digital dengan target capaian peserta dapat memahami lanskap bisnis dalam konteks digital saat ini.

2. Penjelasan terperinci mengenai aktivitas dan tahapan yang dilalui oleh konsumen dalam mengambil keputusan pembelian di berbagai platform online dengan target capaian peserta memahami pentingnya informasi mengenai perilaku konsumen khususnya di era digital sebagai dasar perancangan strategi komunikasi pemasaran.

3. Penyampaian tutorial penyusunan strategy targeting untuk menyasar konsumen di platform online dengan target capaian peserta dapat menyusun profil khalayak sasaran untuk bisnisnya masing-masing terutama di media sosial.

4. Tutorial pemanfaatan hasil analisa informasi aktivitas konsumen untuk mengembangkan strategi komunikasi pemasaran di platform online dengan target capaian peserta dapat menyusun rencana sederhana untuk strategi komunikasi pemasaran bisnisnya berdasarkan informasi terkait perilaku konsumen di media sosial.

5. Diskusi interaktif atau sharing pendapat diantara para peserta pelatihan dengan difasilitasi oleh seorang fasilitator yang dalam hal ini adalah dosen pelaksanan kegiatan pengabdian pada masyarakat dengan target capaian terjadinya komunikasi dua arah antara peserta dan fasilitator kegiatan utamanya untuk memaksimalkan proses sharing knowledge dan peningkatan kompetensi peserta kegiatan.

6. Evaluasi kegiatan dengan menyebarkan kuesioner kepada para peserta, dengan target capaian untuk mengetahui umpan balik guna melakukan analisis situasi dan sebagai bahan masukan penyelenggaraan kegiatan serupa di masa selanjutnya.

\section{HASIL DAN PEMBAHASAN}

Kegiatan pelatihan diawali dengan pemaparan mengenai latar belakang dan analisis situasi perkembangan teknologi dan bisnis di Indonesia, kemudian materi masuk kepada penjelasan mengenai "peta perjalanan konsumen" dalam proses pengambilan keputusan pembeliannya dalam era digital. Di akhir peserta juga antusias saat diberikan penjelasan mengenai berbagai solusi yang dapat dilakukan dalam konteks mengelola media sosial untuk kepentingan bisnis mereka masing-masing. Solusi-solusi ini disusun dari hasil penelitian terdahulu, khususnya terfokus pada tahapan 1) 
pembentukan pengetahuan konsumen, 2) pemasaran; (P3) menyusun profil khalayak menarik perhatian, 3) pemberian informasi yang sasaran untuk bisnisnya masing-masing dibutuhkan oleh konsumen, 4) tahap pembelian terutama di media sosial; (P4) menyusun dan tahap 5) tahap penularan atau rencana sederhana untuk strategi komunikasi mempengaruhi konsumen lain.

Secara terperinci proses penyampaian pemasaran bisnisnya berdasarkan informasi terkait perilaku konsumen di media sosial; (P5) materi dan tutorial dalam kegiatan pengabdian kepada masyarakat ini dapat dilihat pada Gambar 1.

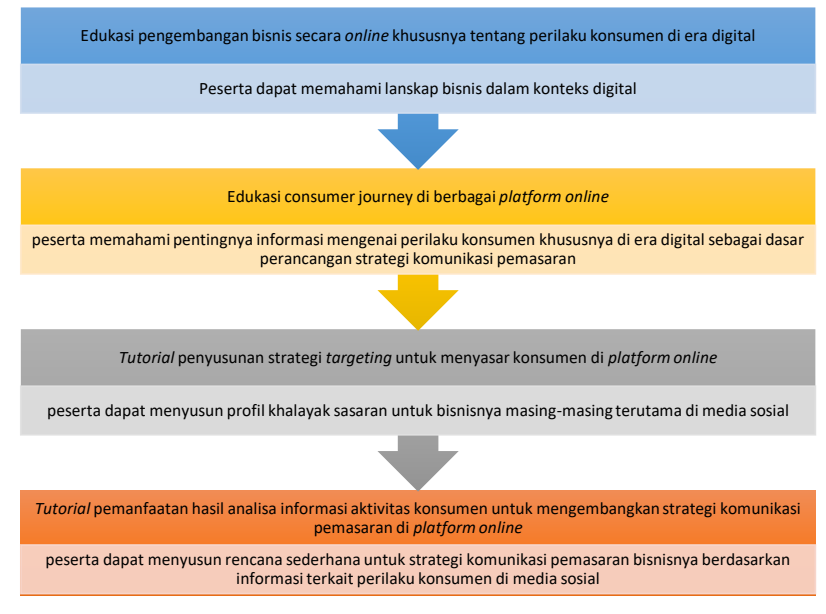

Gambar 1. Proses dan Capaian Kegiatan

Dari hasil evaluasi kegiatan melalui kuesioner yang dibagikan, diperoleh data dan informasi mengenai kepuasan peserta terhadap kegiatan pengabdian masyarakat ini.

Tampak pada Gambar 2, seluruh peserta merasakan manfaat dari kegiatan ini. Seluruh peserta (100\%) memiliki tanggapan positif dengan memberikan persetujuan bahwa dengan mengikuti kegiatan ini dapat membantu mereka dalam: (P1) memahami lanskap bisnis dalam konteks digital yang tengah berlangsung saat ini; (P2) memahami pentingnya informasi mengenai perilaku konsumen khususnya di era digital sebagai dasar perancangan strategi komunikasi

mengikuti kegiatan dengan baik dengan terjadinya komunikasi dua arah antara peserta dan fasilitator kegiatan sehingga memaksimalkan proses sharing knowledge dan peningkatan kompetensi peserta kegiatan.

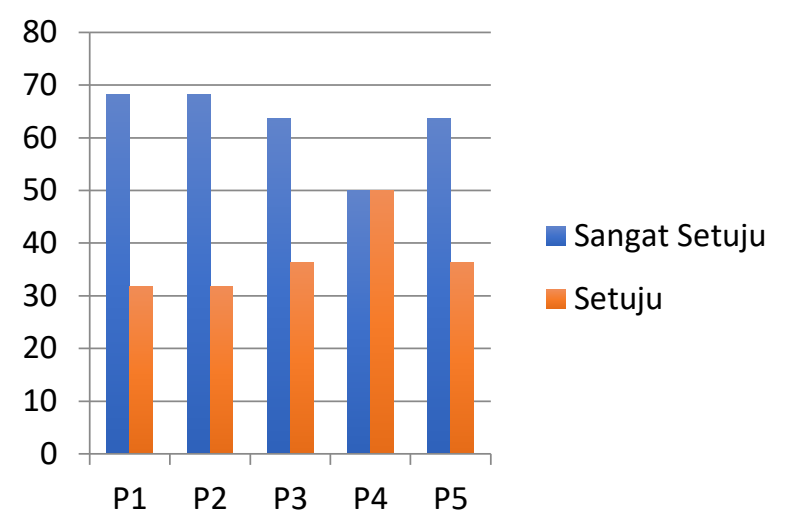

Gambar 2. Hasil Evaluasi Kegiatan

Disampaikan juga oleh peserta bahwa materi yang disampaikan sesuai dengan harapan mereka dan diharapkan kegiatan serupa dapat dilaksanakan secara berkala. Masukkan yang disampaikan peserta adalah ingin memperoleh modul terkait materi yang disampaikan sebagai salah satu sumber belajar lebih lanjut. Secara keseluruhan kegiatan pengabdian kepada masyarakat ini berjalan dengan lancar dan diraskaan manfaatnya oleh seluruh peserta. 


\section{KESIMPULAN DAN SARAN}

Melalui kegiatan pengabdian kepada masyarakat ini disimpulkan bahwa peserta kegiatan dapat:

a. Memahami lanskap bisnis dalam konteks digital yang tengah berlangsung saat ini.

b. Memahami pentingnya informasi mengenai perilaku konsumen khususnya di era digital sebagai dasar perancangan strategi komunikasi pemasaran.

c. Menyusun profil khalayak sasaran untuk bisnisnya masing-masing terutama di media sosial.

d. Menyusun rencana sederhana untuk strategi komunikasi pemasaran bisnisnya berdasarkan informasi terkait perilaku konsumen di media sosial.

e. Mampu mengikuti kegiatan dengan baik dengan terjadinya komunikasi dua arah antara peserta dan fasilitator kegiatan sehingga memaksimalkan proses sharing knowledge dan peningkatan kompetensi peserta kegiatan.

Saran yang dapat disampaikan berdasarkan kegiatan pengabdian kepada masyarakat ini, yaitu:

a. Kegiatan dapat dilaksanakan secara berkelanjutan sehingga dapat dipantau progres capaian dari peserta pelatihan.

b. Dapat diberikan modul pelatihan kepada peserta sebagai sumber belajar untuk dapat lebih memperkaya pengetahuan dan wawasan.

\section{UCAPAN TERIMA KASIH}

Penulis memberikan ucapan terima kasih kepada Lembaga Pusat Pengabdian Masyarakat Universitas Mercu Buana dan juga Jajaran Pemerintahan Kota Tangerang, khususnya Staff Kelurahan Cibodas atas dukungan dalam penyelenggaraan kegiatan PPM ini.

\section{DAFTAR PUSTAKA}

Briandana, R., Pribadi, E., \& Balaya, S. (2020). Mapping The Convergence Trends of Television Broadcasting Media in Indonesia. Bricolage: Jurnal Magister IImu Komunikasi, 6(2), 147-158.

Dwityas, N. A. (2016). Komunikasi dan Pariwisata: Peran User Generated Content bagi Traveler dalam Media Sosial. JURNAL SIMBOLIKA: Research and Learning in Communication Study, 2(1).

Dwityas, N. A., Briandana, R., \& Aulia, P. (2020). Consumer journey of culinary products through social media in Indonesia. Humanities and Social Science Review, 8(1), 306-314.

Dwityas, N. A., Mulyana, A., Hesti, S., Briandana, R., \& Putrianti, M. K. (2020). Digital Marketing Communication Strategies: The Case of Indonesian News' Portals. International Journal of Economics and Business Administration, VIII(Issue 3), 307316.

Gane, N., \& Beer, D. (2008). New Media The Key Concept. Oxford, New York: Berg Publishers. 
Harrigan, P., Evers, U., Miles, M., \& Daly, T. Sidali, K. L., Kastenholz, E., \& Bianchi, R. (2015). (2017). Customer Engagement with Tourism Food Tourism, Niche Markets and Products Social Media Brands. Tourism Management, in Rural Tourism: Combining the Intimacy 59, 597-609. Model and The Experience Economy as a

Hollebeek, L. D., Glynn, M. S., \& Brodie, R. J. Rural Development Strategy. Journal of (2014). Consumer Brand Engagement in Sustainable Tourism, 23(8-9), 1179-1197.

Social Media: Conceptualization, scale Umkm.tangerangkota.go.id. (2020, Januari 20). development and validation. Journal of UMKM di Kota Tangerang Bertambah Interactive Marketing, 28(2), 149-165.

Kim, W. G., Lee, C., \& Hiemstra, S. J. (2004). Effects of an Online Virtual Community on Customer Loyalty and Travel Product Ribuan dalam Tiga Tahun. Portal UMKM Kota Tangerang. Diakses dari https://umkm.tangerangkota.go.id/list-berit a/berita/kFXi4e

Purchases. Tourism Management, 25(3), 343-355.

Mulyana, A., Briandana, R., \& Rekarti, E. (2020). Wang, X., Yu, C., \& Wei, Y. (2012). Social Media Peer Communication and Impacts on ICT and Social Media as a Marketing Communication Platform in Facilitating Purchase Intentions: A Consumer Socialization Framework. Journal of Interactive Marketing, 26(4), 198-208.

Social Engagement in the Digital Era.

International Journal of Innovation, Creativity and Change, 13(5), 1-16. 